\title{
Microstructure of Bimetallic Pt-Pd Nanoparticles Under Working Conditions
}

Tyne R. Johns ${ }^{1}$, Jason R. Gaudet ${ }^{1,2}$, Eric J. Peterson ${ }^{1}$, Jeffrey T. Miller ${ }^{3}$, Chang H. Kim ${ }^{4}$, Michael P. Balogh $^{4}$ and Abhaya K. Datye ${ }^{1}$

1. University of New Mexico, Department of Chemical \& Nuclear Engineering, Albuquerque, NM, USA

2. University of Michigan, Department of Chemical Engineering, Ann Arbor, MI, USA

3. Argonne National Laboratory, Advanced Photon Source, Argonne, IL, USA

4. General Motors Global R\&D, Chemical and Materials Systems Lab, Warren, MI, USA

Diesel oxidation catalysts (DOCs) are currently composed of platinum (Pt) and palladium (Pd). Pt catalysts are very active, but Pt sinters and has poor durability under oxidizing conditions. Reports in the literature show that Pd improves the durability of Pt catalysts but it has been unclear how Pd enhances the durability and performance of these catalysts $[1,2]$. Esparza et al. demonstrated that core-shell Pt-Pd structures with a surface Pd layer could be prepared via colloidal routes [3]. Ezekoye et al. suggested that in their aged Pt-Pd catalysts, particles under $2.5 \mathrm{~nm}$ were primarily Pt-rich while those greater than $2.5 \mathrm{~nm}$ were Pd-rich [2]. However, it is important to study these catalysts under oxidizing conditions, as encountered in diesel oxidation catalysts. Hence, the extent of alloying during working conditions, how $\mathrm{Pd}$ modifies Pt, and whether Pd is present as a surface layer or as Pd, needs further study by HRTEM and EDS. Aging under oxidizing conditions may change the morphology, in which case the core-shell structures may not be stable under working conditions.

Using incipient wetness impregnation, we prepared $0.8 \mathrm{wt}$ \% monometallic Pt and Pd catalysts and a 1.3 wt. \% Pt-Pd catalyst (40:60 atomic ratio) on two supports: La-stabilized alumina and $\gamma$-alumina. The $\mathrm{Pt}$ and Pd loadings were determined via energy dispersive $\mathrm{X}$-ray spectroscopy (EDS). The samples were calcined in ambient air in a box furnace at $600^{\circ} \mathrm{C}$ for $4 \mathrm{hr}$, reduced in flowing $7 \% \mathrm{H}_{2} / \mathrm{N}_{2}$ in a quartz tube furnace at $550^{\circ} \mathrm{C}$ for $2 \mathrm{hr}$, then aged in ambient air in a box furnace at $750^{\circ} \mathrm{C}$ for $10 \mathrm{hr}$. The catalysts in this state are referred to as "aged." A portion of each catalyst was reduced in $7 \% \mathrm{H}_{2} / \mathrm{N}_{2}$ for $1 \mathrm{hr}$ at $250^{\circ} \mathrm{C}$, and these catalysts are referred to as "aged plus reduced."

A JEOL 2010F 200kV FASTEM FEG (field emission gun) TEM/STEM ((scanning) transmission electron microscope) was used to acquire high angle annular dark field (HAADF) images. For compositional analysis by EDS, we used a probe size of $1.0 \mathrm{~nm}$ to get adequate counting statistics. For high resolution compositional mapping, we also used a JEOL JEM 2100F AC (aberration-corrected STEM). The nominal point resolution and ultimate probe size for this instrument was similar to that of the JEOL 2010F, but the aberration corrector provides a much higher probe current for EDS analysis.

STEM/EDS was performed on the aged plus reduced La-alumina-supported catalysts. STEM results showed that the Pt-Pd/La- $\mathrm{Al}_{2} \mathrm{O}_{3}$ had a bimodal distribution of particle sizes. Figure 1 shows two images taken at different magnifications, which shows a dispersed phase coexisting with large bimetallic nanoparticles. The overall composition of this sample was 38 at. \% Pt and 62 at. \% Pd, as determined by EDS. However, the average composition of the large metallic particles was Pt-rich. It was important to identify the dispersed phase in the bimetallic catalyst to help us explain the discrepancy between the overall EDS analysis and the analysis of the large particles. EDS mapping allowed us to derive the average composition of the particles, as well as the dispersed phase. A spectrum image was obtained, and specific regions of the image could then be chosen and a spectrum derived for all the pixels in the 
chosen area. A sum spectrum was obtained which determined the composition over the entire image. Then the residual dispersed phase could be obtained by subtracting the region around each large particle from the sum spectrum. It was found that the residual contained 72 at. \% Pd which suggests that the dispersed phase in these catalysts is Pd-rich while the large bimetallic particles are Pt-rich.

Figure 2 shows the $\mathrm{Pt}-\mathrm{Pd} / \mathrm{La}-\mathrm{Al}_{2} \mathrm{O}_{3}$ catalyst after aging in air at $750^{\circ} \mathrm{C}$ for $10 \mathrm{hr}$ and reduction at $250^{\circ} \mathrm{C}$ in $7 \% \mathrm{H}_{2} / \mathrm{N}_{2}$ for $1 \mathrm{hr}$. The different areas shown in the figure were analyzed using EDS. A sum spectrum was taken which showed a composition of 74 at. \% Pt and 26 at. \% Pd, as shown in the table below. The individual regions shown in Figure 2 were also analyzed, and the composition of $\mathrm{Pt}$ and $\mathrm{Pd}$ in these areas are also shown in the table. Pd was only slightly richer on the surface of the nanoparticle (31\% vs. 26\%), which shows that under working conditions, these catalysts do not form a core-shell morphology. These results were corroborated with EXAFS, XANES, and XRD. Our results suggest that $\mathrm{Pd}$ does not significantly slow down the rate of sintering of $\mathrm{Pt}$, and large $\mathrm{Pt}$ particles that are alloyed with $\mathrm{Pd}$, are seen on the aged catalyst.

\section{References:}

[1] K. Persson, K. Jansson, and S.G. Järås, J. Catal. 245 (2007) p. 401.

[2] O.K. Ezekoye et al., J. Catal. 280 (2011) p. 125.

[3] R. Esparza et al., J. Nanopart. Res. 15 (2013).

[4] Financial Support: NSF GOALI CBET-1067803, NSF IGERT DGE-0504276, and NSF PIRE OISE0730277. The EDS spectral analysis was performed at General Motors Global R\&D.
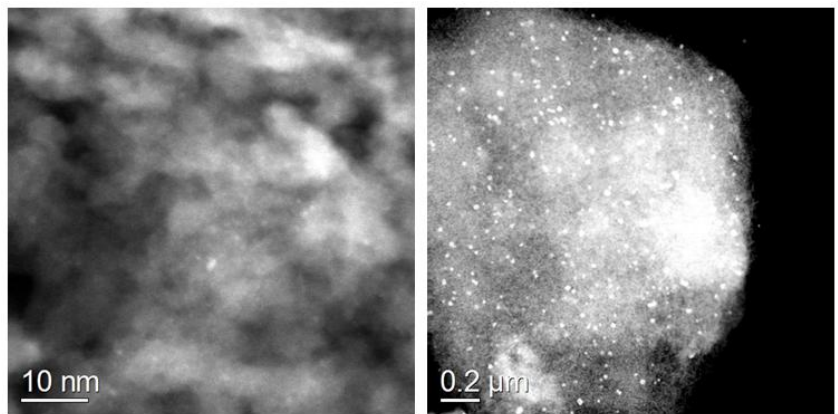

Figure 1. STEM image of (a) dispersed phase and (b) large particles in the aged plus reduced Pt-Pd/La$\mathrm{Al}_{2} \mathrm{O}_{3}$ catalyst.

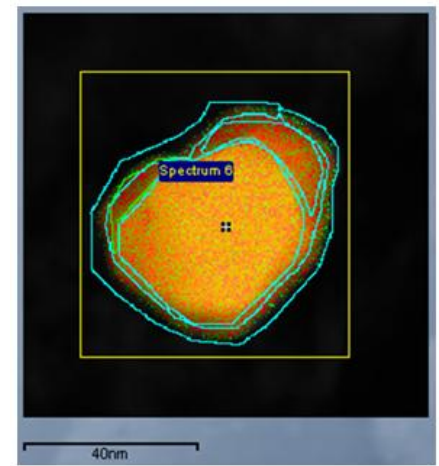

\section{\begin{tabular}{l|l|l|l|l|l} 
Spectrum & Wt \% Pd & Wt \% Pt & At \% Pd & At \% Pt
\end{tabular}}

\begin{tabular}{|c|c|c|c|c|c|}
\hline Sum & 16.1 & 83.9 & 26.1 & 73.9 \\
\hline Perimeter & 20.0 & 80.0 & 31.4 & 68.6 \\
\hline Top & 16.6 & 83.4 & 26.7 & 73.3 \\
\hline Central & 15.7 & 84.3 & 25.5 & 74.5 \\
\hline Left & 14.2 & 85.8 & 23.3 & 76.7 \\
\hline
\end{tabular}

Figure 2. AC-STEM image of a Pt-Pd/La- $\mathrm{Al}_{2} \mathrm{O}_{3}$ catalyst aged in air at $750^{\circ} \mathrm{C}$ for $10 \mathrm{hr}$ and reduced at $250^{\circ} \mathrm{C}$ in $7 \% \mathrm{H}_{2} / \mathrm{N}_{2}$ for $1 \mathrm{hr}$ with superimposed results from EDS mapping. 